\title{
Blockade of p38 Mitogen-Activated Protein Kinase Inhibits Murine Sclerodermatous Chronic Graft-versus-Host Disease
}

\author{
Takashi Matsushita, ${ }^{*}$ Mutsumi Date, ${ }^{*}$ Miyu Kano, ${ }^{*}$ Kie Mizumaki, ${ }^{*}$ Momoko Tennichi, ${ }^{*}$ Tadahiro Kobayashi, \\ Yasuhito Hamaguchi, ${ }^{*}$ Minoru Hasegawa, ${ }^{\dagger}$ Manabu Fujimoto, ${ }^{\ddagger}$ and Kazuhiko Takehara*
}

From the Department of Dermatology, * Faculty of Medicine, Institute of Medical, Pharmaceutical and Health Sciences, Kanazawa University, Kanazawa; the Department of Dermatology, ${ }^{\dagger}$ University of Fukui, Fukui; and the Department of Dermatology, ${ }^{\ddagger}$ Faculty of Medicine, University of Tsukuba, Tsukuba, Japan

\author{
Accepted for publication \\ December 19, 2016. \\ Address correspondence to \\ Takashi Matsushita, M.D., Ph.D., \\ Department of Dermatology, \\ Faculty of Medicine, Institute of \\ Medical, Pharmaceutical and \\ Health Sciences, Kanazawa \\ University, Kanazawa 920-8641, \\ Japan. E-mail: t-matsushita@ \\ med.kanazawa-u.ac.jp.
}

\begin{abstract}
Bone marrow transplantation (BMT) of B10.D2 mice into sublethally irradiated BALB/C mice across minor histocompatibility loci is a well-established animal model for human sclerodermatous chronic graft-versus-host disease (Scl-cGVHD) and systemic sclerosis (SSc). The p38 mitogen-activated protein kinase (MAPK) pathway is a key regulator of inflammation and cytokine production. Furthermore, the activation of p38 MAPK plays an important role in collagen production in SSc. We investigated the effects of p38 MAPK inhibitor, VX-702, on Scl-cGVHD mice. VX-702 was orally administered to Scl-cGVHD mice from day 7 to 35 after BMT. We compared skin fibrosis of Scl-cGVHD mice between the VX-702treated group and control group. Allogeneic BMT increased the phosphorylation of p38 MAPK in the skin. The administration of VX-702 attenuated the skin fibrosis of Scl-cGVHD compared to the control mice. Immunohistochemical staining showed that VX-702 suppressed the infiltration of $\mathrm{CD}^{+}{ }^{+} \mathrm{T}$ cells, $\mathrm{CD}^{+} \mathrm{T}$ cells, and $\mathrm{CD} 11 \mathrm{~b}^{+}$cells into the dermis of Scl-cGVHD mice compared to the control mice. VX-702 attenuated the mRNA expression of extracellular matrix and fibrogenic cytokines, such as IL- 6 and IL-13, in the skin of Scl-cGVHD mice. In addition, VX-702 directly inhibited collagen production from fibroblasts in vitro. VX-702 was shown to be a promising candidate for use in treating patients with Scl-cGVHD and SSc. (Am J Pathol 2017, 187: 841-850; http://dx.doi.org/10.1016/ j.ajpath.2016.12.016)
\end{abstract}

Systemic sclerosis ( $\mathrm{SSc}$ ) is an autoimmune disease marked by excessive extracellular matrix (ECM) deposition in the skin and internal organs. ${ }^{1}$ The abnormal accumulation of type I and III collagen, fibronectin 1 , and transforming growth factor (TGF)- $\beta$ is a key mediator of ECM accumulation in pathological states in SSc. ${ }^{2}$ Although the etiology of SSc remains unknown, three major abnormalities-autoimmunity, vasculopathy, and fibrosis - are considered crucial in the pathophysiology of SSc. ${ }^{3}$ Chronic graft-versus-host disease (cGVHD) emerges from alloreactive reactions between donor-derived immune cells and host cell populations.

Mouse models are critical tools for furthering our understanding of the pathophysiology underlying this disease. Transplantation of bone marrow (BM) and splenocytes of B10.D2 mice (major histocompatibility complex haplotype $\mathrm{H}-2^{\mathrm{d}}$ ) into sublethally irradiated BALB/c
$\left(\mathrm{H}-2^{\mathrm{d}}\right)$ mice across minor histocompatibility loci is a well-established animal model for human sclerodermatous cGVHD (Scl-cGVHD) and SSc, both of which show many clinical similarities with human SSc. ${ }^{4}$ Histologic analysis of the initial stages of both SSc and Scl-cGVHD shows infiltration of mononuclear cells into the dermis, with an associated increase in collagen synthesis. ${ }^{5}$ Skin thickening and pulmonary fibrosis develop 3 weeks after BM transplantation (BMT) in Scl-cGVHD mice. ${ }^{6}$ Therefore, murine Scl-cGVHD is an ideal animal model for investigating the pathogenesis of SSc and novel therapeutic candidates for SSc.

\footnotetext{
Supported by Ministry of Health, Labour, and Welfare of Japan Research on Intractable Diseases grant 201442041A.

T.M. and M.D. contributed equally to this work.

Disclosures: None declared.
} 
The $\mathrm{p} 38$ mitogen-activated protein kinase (MAPK) is a key regulator of the signaling cascade controlling cellular responses to cytokines and stress. ${ }^{8-11}$ In mammals, including humans, four isoforms of p38 MAPK (namely, $\mathrm{p} 38 \alpha, \beta, \gamma$, and $\delta$ ) have been identified. The distribution of each p38 MAPK isoform has a different tissue-specific pattern. ${ }^{12,13}$ Although the p38 $\alpha$ MAPK is broadly expressed in various cell types, $p 38 \beta$ is mostly expressed in brain and lung tissues; $\mathrm{p} 38 \gamma$ is uniquely expressed in skeletal muscle and the nervous system; and p38ס is highly expressed in the lung, kidney, uterus, and pancreas. The p38 MAPKs are activated by multiple extracellular stimuli, such as inflammatory cytokines, stress signals (eg, lipopolysaccharide), and osmotic shock. ${ }^{8-11,14}$ The activation of p38 MAPKs is mediated by the phosphorylation of Thr180 and Tyr182, and activated p38 MAPK results in the transcriptional activation of cytokines and cellular responses. ${ }^{14,15}$ The $\mathrm{p} 38 \alpha$ isoform plays the most important regulatory role of the inflammatory response; thus, it has been considered a therapeutic target in various diseases, such as rheumatoid arthritis and acute coronary syndrome. ${ }^{16,17}$ Clinical trials of VX-702, a highly selective inhibitor of the $\mathrm{p} 38 \alpha$ isoform of MAPK, have shown modest clinical efficacy, together with the transient suppression of inflammation biomarkers, in rheumatoid arthritis patients. ${ }^{16} \mathrm{VX}$ 702 has little or no central nervous system penetration, whereas other p38 $\alpha$ MAPK inhibitors, such as SCIO-469 and pamapimod, have unacceptable adverse events on the central nervous system. ${ }^{18,19}$

Fibroblasts from human SSc have been found to show constitutive phosphorylation and activation of p38 MAPK. $^{20,21}$ Furthermore, the p38 MAPK inhibitor suppressed the up-regulated expression of type I collagen in SSc fibroblasts. ${ }^{21}$ Thus, p38 MAPK plays an important role in the pathogenesis of SSc. The current study investigated the effects of oral blockade of the p38 MAPK VX-702 on Scl-cGVHD mice.

\section{Materials and Methods}

\section{Mice}

B10.D2 $\left(\mathrm{H}-2^{\mathrm{d}}\right)$ and BALB/c $\left(\mathrm{H}-2^{\mathrm{d}}\right)$ mice were purchased from Japan SLC (Shizuoka, Japan). The mice were housed in a specific pathogen-free barrier facility. All studies and procedures were approved by the Committee on Animal Experimentation of Kanazawa University Graduate School of Medical Science (Kanazawa, Japan).

\section{Bone Marrow Transplantation}

In this study, 8- to 12-week-old male B10.D2 and female $\mathrm{BALB} / \mathrm{c}$ mice were used as donors and recipients, respectively. BM was $\mathrm{T}$ cell depleted with anti-Thy 1.2 microbeads (Miltenyi Biotech, Auburn, CA). BALB/c recipients were irradiated with 800 cGy (MBR-1520R; Hitachi, Tokyo,
Japan) and were injected via the tail vein with $10 \times 10^{6}$ T-cell-depleted $\mathrm{BM}$ and $10 \times 10^{6}$ splenocytes in $0.5 \mathrm{~mL}$ phosphate-buffered saline to generate Scl-cGVHD (allogeneic BMT). A control syngeneic group of female BALB/c mice received male $\mathrm{BALB} / \mathrm{c}$ T-cell-depleted $\mathrm{BM}$ and splenocytes (syngeneic BMT).

\section{Contact Hypersensitivity Response}

Mice were sensitized on the shaved abdominal flank skin with $0.5 \%$ 2,4-dinitrofluorobenzene (Sigma-Aldrich, St. Louis, MO), in acetone and olive oil $(4: 1 \mathrm{v} / \mathrm{v})$ for 2 consecutive days. Five days later, contact hypersensitivity was elicited by applying $0.25 \%$ 2,4-dinitrofluorobenzene on the right ear. The left ear was treated with acetone/olive oil alone as a control. Ear thickness was measured in a blinded manner (M.K. and T.K.) using a micrometer before and after the challenge every 24 hours for 120 hours.

\section{Reagents}

VX-702 (Cayman Chemical, Ann Arbor, MI) is an inhibitor of p38 MAPK, binding to both $\mathrm{p} 38 \alpha$ and $\mathrm{p} 38 \beta$ in an ATP-competitive manner. VX-702 was orally administered to allogenic recipients at a dose of $10 \mathrm{mg} / \mathrm{kg}$ from day 7 to 34 after BMT. The oral dose of VX-702 has been described previously. ${ }^{17}$ Control mice received distilled water only.

\section{cGVHD Skin Score}

The clinical cGVHD score was obtained as previously described. ${ }^{22}$ Mice were weighed every 6 days after BMT and scored for skin lesion of cGVHD, beginning at approximately day 18 . The scoring was as follows: healthy appearance, 0 ; skin lesions with alopecia equal to or less than $1 \mathrm{~cm}^{2}$ in area, 1; skin lesions with alopecia 1 to $2 \mathrm{~cm}^{2}$ in area, 2; skin lesions with alopecia 1 to $5 \mathrm{~cm}^{2}$ in area, 3 ; skin lesions with alopecia 5 to $10 \mathrm{~cm}^{2}$ in area, 4 ; skin lesions with alopecia 10 to $15 \mathrm{~cm}^{2}$ in area, 5; skin lesions with alopecia 15 to $20 \mathrm{~cm}^{2}$ in area, 6; and skin lesions with alopecia $>20 \mathrm{~cm}^{2}$ in area, 7 . The skin lesion area was traced on a paper, and the traced area was scanned and measured using the ImageJ software version $1.51(\mathrm{NIH}$, Bethesda, MD; http://rsb.info.nih.gov/ij). Furthermore, animals were assigned 0.4 points for skin disease (lesions or scaling) on the tail and 0.3 points each for lesions on the ears and paws. The minimum and maximum scores were thus 0 and 8 , respectively. Final scores for dead animals were maintained in the data set for the remaining time points.

\section{Histologic Analysis}

The skin, lungs, and colon were fixed in $10 \%$ formalin and embedded in paraffin. Sections $(6 \mu \mathrm{m}$ thick) were stained with hematoxylin and eosin and Masson's trichrome. Dermal collagen thickness was measured from the upper 
dermis to the lower dermis by microscopy. The blue-stained area on Masson's trichrome staining, representing collagen, was quantified using ImageJ software version 1.51.

\section{Immunohistochemical Staining of the Skin}

The skin samples from Scl-cGVHD mice were removed and frozen in liquid nitrogen using embedding medium for frozen tissue specimens (Tissue-Tek OCT compound; Sakura Finetek, Tokyo, Japan) and stored at $-70^{\circ} \mathrm{C}$ until use. Frozen sections ( $5 \mu \mathrm{m}$ thick) were immediately fixed in cold acetone and were incubated with rat anti-mouse CD4 monoclonal antibody (RM4-5 clone; BD Biosciences, San Jose, CA), rat anti-mouse CD8 monoclonal antibody (53-6.7 clone; BD Biosciences), rat anti-mouse $\mathrm{CD} 11 \mathrm{~b}$ monoclonal antibody (M1/70 clone; BD Biosciences), or phospho-p38 MAPK (pT180/pY182; BioLegend, San Diego, CA). Sections were then incubated sequentially with a biotinylated goat anti-rabbit IgG secondary antibody (BD Biosciences), followed by incubation with horseradish peroxidase-conjugated avidin-biotin complexes (Vectastain ABC method; Vector Laboratories, Burlingame, CA). Sections were washed three times with phosphate-buffered saline between incubations, developed with 3,3'diaminobenzidine tetrahydrochloride and hydrogen peroxide, and then counterstained with hematoxylin. Positive cells were counted in five high-power fields, and the average/high-power field was calculated.

\section{Preparation of Skin Cell Suspensions for Flow Cytometry}

A $2 \times 2$-cm piece of depilated back skin was minced and then digested in $7 \mathrm{~mL}$ of RPMI 1640 medium-10\% fetal bovine serum containing $2 \mathrm{mg} / \mathrm{mL}$ collagenase (SigmaAldrich), $1.5 \mathrm{mg} / \mathrm{mL}$ hyaluronidase (Sigma-Aldrich), and $0.03 \mathrm{mg} / \mathrm{mL}$ DNase I (Sigma-Aldrich) at $37^{\circ} \mathrm{C}$ for 90 minutes. Digested cells were then passed through a $70-\mu \mathrm{m}$ cell Falcon Cell Strainer (BD Biosciences) to generate singlecell suspensions. The cell suspension was centrifuged at $300 \times g$ for 10 minutes. The pellet was resuspended in $70 \%$ Percoll solution (GE Healthcare, Uppsala, Sweden), and then overlaid by $37 \%$ Percoll solution (GE Healthcare), followed by centrifugation at $500 \times g$ for 20 minutes at room temperature. Cells were aspirated from the Percoll interface and passed through a 70- $\mu \mathrm{m}$ cell strainer. Subsequently, the cells were harvested by centrifugation and washed.

\section{Fibroblast Culture}

Skin samples $(1 \times 1 \mathrm{~cm})$ were taken from the para-midline lower back region of naive BALB/c mice, as previously described. ${ }^{23}$ To obtain fibroblasts, the tissue was cut into $1-\mathrm{mm}^{3}$ pieces; placed in sterile plastic dishes; and cultured in Dulbecco's modified Eagle's medium (Invitrogen, Carlsbad, CA) containing 10\% heat-inactivated fetal calf serum, $100 \mathrm{U} / \mathrm{mL}$ penicillin (Invitrogen), and $100 \mu \mathrm{g} / \mathrm{mL}$ streptomycin (Invitrogen) at $37^{\circ} \mathrm{C}$ in a humidified $5 \% \mathrm{CO}_{2}$ atmosphere. After 2 to 3 weeks of incubation, outgrowing fibroblasts were detached by brief trypsin treatment and recultured in the medium. Confluent cultures of fibroblasts were serum starved for 12 hours and then pretreated with dimethyl sulfoxide or various concentrations of VX-702. One hour later, cells were stimulated with $10 \mathrm{ng} / \mathrm{mL}$ TGF$\beta 2$ (BioLegend) and incubated for another 24 hours. The supernatant was harvested, and the monolayers were washed. The cells were used immediately in experiments, as indicated. All experiments used fibroblasts between passages 2 and 5, depending on the number of cells obtained initially from the tissue samples. Cultured fibroblasts were adherent to the dish and maintained the typical spindleshaped aspect. The purity of fibroblasts, as confirmed by flow cytometry, was $>99 \%$ with no leukocytes found in the harvested cells (data not shown). In each experiment, all of the cell lines were examined at the same time and under the same conditions of culture (eg, cell density, passage, and days after plating).

\section{RT-PCR}

Total RNA was isolated from frozen skin specimens or cultured fibroblasts using RNeasy spin columns (Qiagen, Hilden, Germany) and digested with DNase I (Qiagen) to remove chromosomal DNA. Total RNA was reverse transcribed to cDNA using a reverse transcription system with random hexamers (Promega, Southampton, UK). Cytokine mRNA was analyzed using real-time RT-PCR quantification (Applied Biosystems, Foster City, CA). Real-time RT-PCR was performed on an ABI Prism 7000 sequence detector (Applied Biosystems). Glyceraldehyde-3phosphate dehydrogenase was used to normalize the mRNA. The relative expression of real-time RT-PCR products was determined according to the $\Delta \Delta \mathrm{Ct}$ method to compare target gene and glyceraldehyde-3-phosphate dehydrogenase mRNA expression.

\section{Determination of Collagen Content and Procollagen I a1 Content}

Collagen content of fibroblast culture supernatant was determined using QuickZyme Total Collagen Assay (QuickZyme Biosciences, Leiden, the Netherlands), according to the manufacturer's instructions. The procollagen I $\alpha 1$ content of the inflamed skin was determined using the Mouse Pro-Collagen I Alpha 1 enzyme-linked immunosorbent assay kit (Abcam, Cambridge, MA), according to the manufacturer's instructions.

\section{Statistical Analysis}

All data are shown as means \pm SEM. The significance of differences between sample means was determined by $t$-test. 


\section{Results}

Phosphorylation of p38 MAPK Is Augmented in the Inflamed Skin from Scl-cGVHD Mice

The p38 MAPK plays a critical role in the production of cytokines and inflammation. ${ }^{11}$ Activation of p38 MAPK is mediated by the phosphorylation of Thr180 and Tyr182. To investigate whether the phosphorylation of p38 MAPK (Thr180/Tyr182) increases after allogeneic transplantation, p38 MAPK phosphorylation in the inflamed skin was measured by immunohistochemical staining of the skin 14 days after allogeneic BMT (Figure 1). Phosphorylation of p38 MAPK occurred in both the nuclear and cytoplasmic compartments of cells (Figure 1A). When compared with syngeneic BMT, phosphorylation of p38 MAPK was significantly higher in the inflamed skin 14 days after BMT (Figure 1B). Therefore, p38 MAPK was activated after allogeneic BMT.
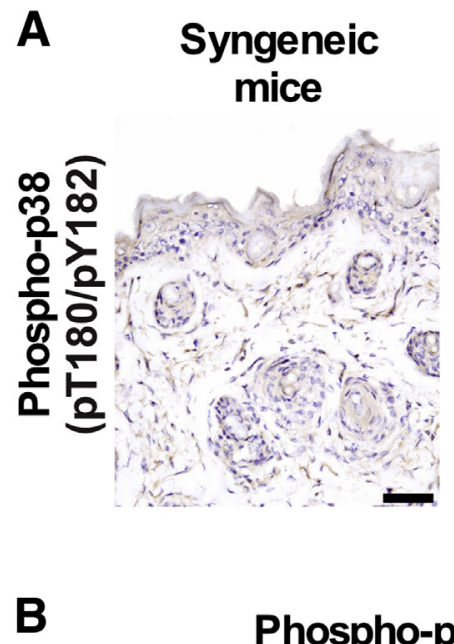

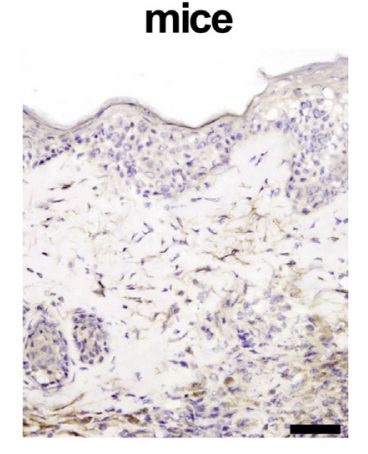

\section{Scl-cGVHD mice}

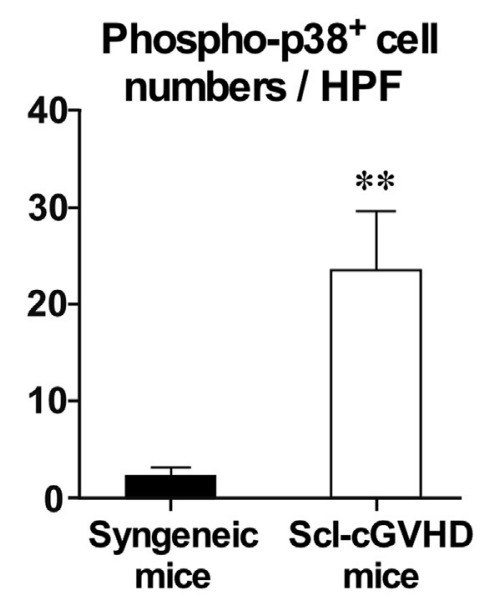

Figure 1 Increased phosphorylation of p38 MAPK in Scl-cGVHD model. A: The representative phosphorylated p38 MAPK (pT180/pY182) positive cells in the skin sections from groups of syngeneic and Scl-cGVHD mice were investigated at day 14 after bone marrow transplantation (BMT). B: The number of phosphorylated p38 MAPK (pT180/pY182) cells per highpower field (HPF) in the skin sections was investigated at day 14 after BMT. All data are representative of two independent experiments. Data are expressed as means \pm SEM (B). $n=4$ to 6 mice per group (B). ${ }^{* *} P<0.01$. Scale bar $=50 \mu \mathrm{m}(\mathbf{A})$.

\section{VX-702 Administration Attenuates Scl-cGVHD}

To determine whether the p38 MAPK inhibitor affects skin fibrosis in Scl-cGVHD mice, the p38 MAPK inhibitor, VX-702, was orally administrated to allogeneic BMT recipients from day 7 to day 35 after BMT. Skin fibrosis and alopecia develop at approximately 20 days after BMT in Scl-cGVHD mice. ${ }^{6}$ In this study, skin fibrosis and alopecia developed 18 days after BMT in the water-treated (control) group, whereas the development of skin fibrosis and alopecia in the VX-702-treated group was delayed to 24 days after BMT. In addition, VX-702 treatment significantly improved skin scores in comparison with the control group $(P<0.05)$ (Figure 2A). VX-702 treatment also significantly improved body weight loss in comparison with the control group $(P<0.05)$ (Figure $2 \mathrm{~B})$. A representative image shows a water-treated (control) Scl-cGVHD mouse having severe and extensive skin fibrosis and alopecia, whereas a VX-702-treated mouse shows mild Scl-cGVHD (Figure 2C). These results were also verified by histopathology. The skin was significantly thinner in the VX-702-treated group than in the control group $(P<0.05)$ (Figure 2, D and E). In addition, the fibrotic area in the skin was significantly narrower in the VX-702-treated group than in the control group $(P<0.05)$ (Figure $2, \mathrm{~F}$ and $\mathrm{G}$ ). The procollagen I $\alpha 1$ content in the inflamed skin of the VX-702-treated group also significantly decreased compared with that of the control group $(P<0.05)$ (Figure $2 \mathrm{H}$ ). In addition, the fibrotic area in the lungs and gut was significantly narrower in the VX-702-treated group than in the control group $(P<0.05)$ (Figure 3$)$. Thus, the administration of p38 MAPK inhibitor attenuated the fibrosis of skin, lungs, and gut in Scl-cGVHD mice.

\section{VX-702 Treatment Reduces the Infiltration of Immune Cells into the Skin}

The infiltration of donor cells into skin was observed in early Scl-cGVHD mice but not in syngeneic animals. ${ }^{24}$ To evaluate immune cell infiltration into the skin in mice with Scl-cGVHD, back skin samples obtained 36 days after BMT were stained with anti-CD4, anti-CD8, and anti-CD11b monoclonal antibodies. Immunohistochemical staining revealed that infiltration of $\mathrm{CD}^{+} \mathrm{T}$ cells, $\mathrm{CD}^{+} \mathrm{T}$ cells, and $\mathrm{CD}_{1} \mathrm{~b}^{+}$monocytes/macrophages into the skin was significantly reduced in the VX-702-treated groups compared with the control group $(70 \%, P<0.05 ; 65 \%$, $P<0.05 ; 80 \%, P<0.05$; respectively) (Figure 4, A-F). Fluorescence-activated cell sorting analysis also revealed that infiltration of $\mathrm{CD} 4^{+} \mathrm{T}$ cells, $\mathrm{CD} 8^{+} \mathrm{T}$ cells, and $\mathrm{CD} 11 \mathrm{~b}^{+}$ monocytes/macrophages into the skin was significantly reduced in the VX-702-treated groups compared with the control group $(P<0.05)$ (Figure $4, \mathrm{G}-\mathrm{K})$. In addition, phosphorylated p38 MAPK of skin-infiltrating cells in the VX-702-treated groups was significantly reduced compared with that in the control group (Supplemental 
A
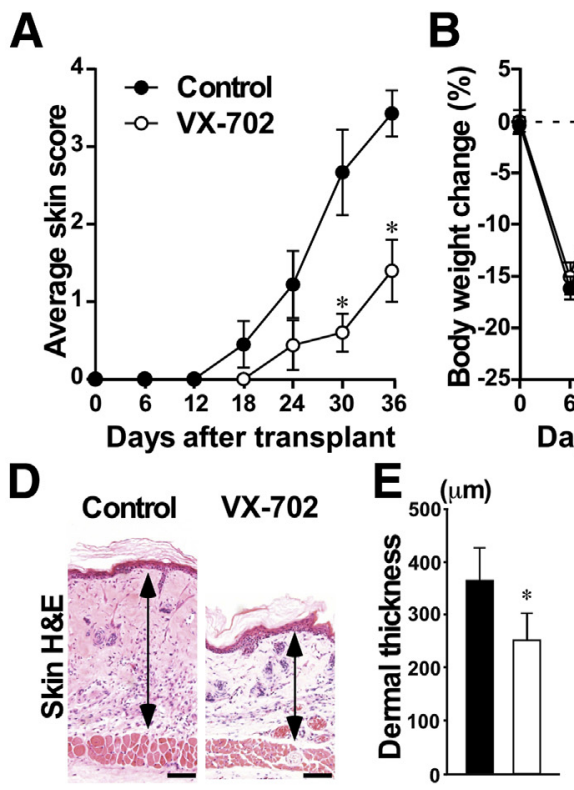

H

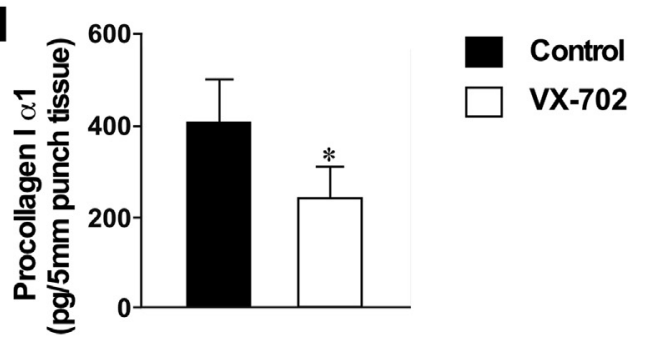

B
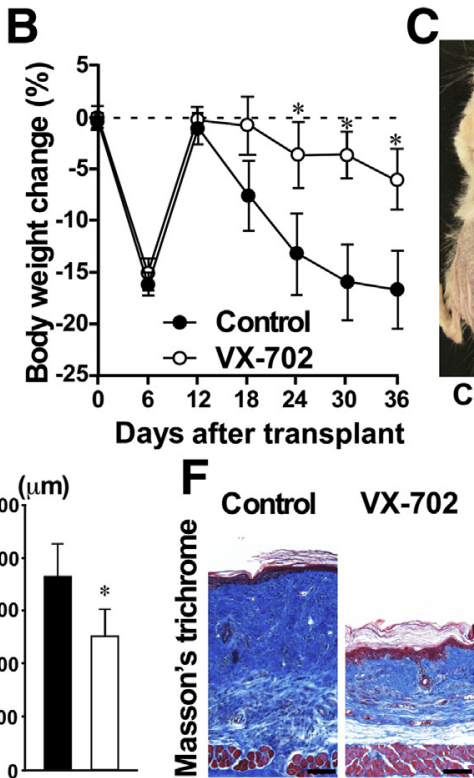

C

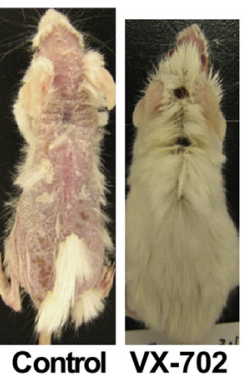

G

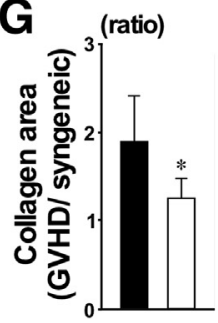

Figure 2 Oral treatment of VX-702 attenuates Scl-cGVHD severity and fibrosis. Recipients were given sterile water (closed circle), or were orally administered $10 \mathrm{mg} / \mathrm{kg}$ per day VX-702 from day 7 to day 35 (open circle). Skin scores (A) and body weight change (B) were monitored every 6 days. C: The respective images were taken 36 days after bone marrow transplantation (BMT). D and E: Dermal thickness was determined by hematoxylin and eosin (H\&E) staining at day 36 after BMT. Arrows indicate dermal thickness. F: Skin fibrosis was determined as the collagen area stained by Masson's trichrome at day 36 after BMT. The blue-stained area, representing collagen, was quantified using ImageJ software version 1.51 (NIH, Bethesda, MD; http:// rsb.info.nih.gov/ij). G: Analysis of the collagen area ratio of Scl-cGVHD/syngeneic mice. H: The procollagen $\mathrm{I} \alpha 1$ content in the inflamed skin at day 36 after BMT was determined by specific enzymelinked immunosorbent assay (closed bar, control; open bar, VX-702). All data are representative of two independent experiments. Data are expressed as means $\pm \operatorname{SEM}(\mathbf{A}, \mathbf{B}, \mathbf{E}, \mathbf{G}$, and $\mathbf{H}) . n=4$ to 6 per group $(\mathbf{A}, \mathbf{B}$, and $\mathbf{H}) .{ }^{*} P<0.05$. Scale bar $=20 \mu \mathrm{m}$ (D and $\mathbf{F})$.

Figure S1). Thus, the inhibition of p38 MAPK significantly reduces the infiltration of immune cells into the skin of Scl-cGVHD mice.

\section{VX-702 Treatment Reduces mRNA Expression of Type I Collagen but Not of Cytokines in the Skin 36 Days after BMT}

Cytokines are critical for the development of tissue fibrosis in SSc and SSc mouse models. ${ }^{25-27}$ Previous studies have suggested that some cytokines, such as IL-1 $\beta$, IL-6, IL-13, and tumor necrosis factor- $\alpha$, regulate dermal fibroblast proliferation and ECM deposition, such as collagen and fibronectin $1 .{ }^{28-31}$ In addition, TGF- $\beta$ and connective tissue growth factor are considered key molecules for tissue fibrosis in SSc mouse models. ${ }^{32}$ By contrast, interferon- $\gamma$, a typical type 1 helper $\mathrm{T}$ cell cytokine, can suppress tissue fibrosis in SSc mouse models. ${ }^{33-35}$ We assessed the type I collagen gene pro $\alpha 2$ (I) collagen (COL1A2), fibronectin 1, and cytokine mRNA expression in the skin from Scl-cGVHD mice by real-time PCR analysis (Figure 5A). The expression of IL- $1 \beta$ mRNA in the skin of the VX-702-treated group was comparable with that of the control group. IL-6 and IL-13 mRNA expression in the VX-702-treated group was significantly decreased compared to that in the control group. Tumor necrosis factor- $\alpha$ and IL-10 mRNA expression in the VX702-treated group tended to decrease compared to the control group but not significantly. By contrast, interferon- $\gamma$ mRNA expression in the VX-702-treated group increased. The expression of TGF- $\beta$ and connective tissue growth factor mRNA did not change between the VX-702-treated and control groups. Consistent with the skin score and histopathology of Scl-cGVHD mice, COL1A2 and fibronectin 1 mRNA expression in the VX-702-treated group were lower than that in the control group. Thus, the administration of p38 MAPK inhibitor attenuated ECM production and expression of fibrogenic cytokines, such as IL-6 and IL-13.

\section{VX-702 Directly Inhibits Collagen Synthesis from Fibroblasts}

We next examined the effects of VX-702 on type I collagen gene expression and collagen protein production using real-time RT-PCR assays and hydroxyproline assays, respectively. Skin fibroblasts were cultured with various concentrations of VX-702 in the presence of TGF- $\beta 2$. As expected, VX-702 significantly reduced COL1A2 mRNA levels in a dose-dependent manner (Figure 5B). This 

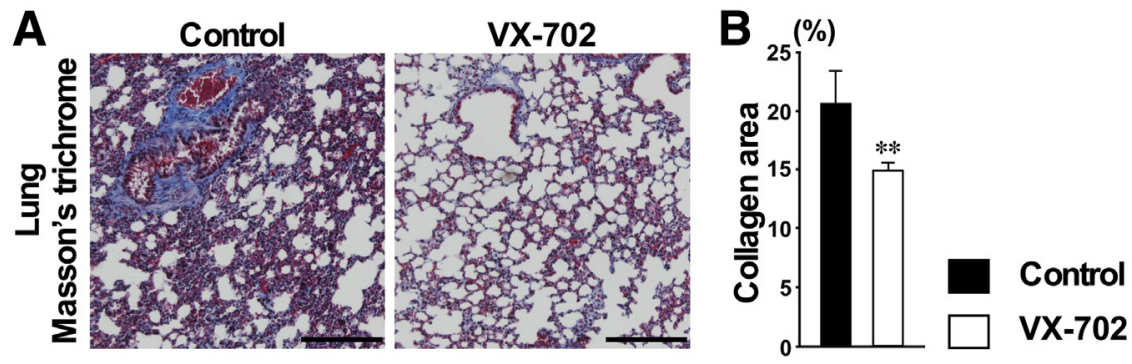

\begin{abstract}
Figure 3 Oral treatment with VX-702 attenuates fibrosis in the lungs and colon. Recipients were given sterile water or were orally administered $10 \mathrm{mg} / \mathrm{kg}$ per day VX-702 from day 7 to day 35. Lung (A) and colon (C) fibrosis was determined as the collagen area stained by Masson's trichrome 36 days after bone marrow transplantation. The blue-stained area, representing collagen, and the total area were quantified using ImageJ software version 1.51 (NIH, Bethesda, MD; http://rsb.info.nih.gov/ij). The ratio of the collagen area/total area in the lungs (B) and colon (D) was analyzed (closed bar, control; open bar, VX-702). All data are representative of two independent experiments. Data are expressed as means \pm SEM (B and D). $n=4$ to 6 mice per group (B and $\mathbf{D}$ ). ${ }^{* *} P<0.01$. Scale bar $=200 \mu \mathrm{m}$ ( $A$ and $\mathbf{C}$ ).
\end{abstract}

decrease in COL1A2 mRNA expression was reflected in a significant reduction in collagen protein production, as determined by a hydroxyproline assay (Figure 5B). Thus, the inhibition of p38 MAPK directly suppressed collagen synthesis in fibroblasts.

\section{Discussion}

This is the first study to reveal the effect of an orally administered p38 MAPK inhibitor on the development of skin fibrosis in a murine Scl-cGVHD model. The phosphorylation of p38 MAPK was augmented in the inflamed skin from murine Scl-cGVHD mice, and orally administered p38 MAPK inhibitor dramatically prevented the development of skin, lung, and gut fibrosis in Scl-cGVHD mice. Furthermore, the infiltration of immune cells into the skin was significantly reduced in p38 MAPK inhibitor-treated Scl-cGVHD mice compared with the control. The p38 MAPK inhibitor significantly reduced the infiltration of immune cells into the skin of Scl-cGVHD mice. The p38 MAPK inhibitor also attenuated mRNA expression of ECM and fibrogenic cytokines, such as IL-6 and IL-13, in the skin of Scl-cGVHD mice. Furthermore, the p38 MAPK inhibitor directly suppressed collagen synthesis from fibroblasts. These results suggest that the p38 MAPK inhibitor VX-702 may be a promising therapeutic agent in human Scl-cGVHD and SSc.

There are three major MAPK subfamilies (namely, extracellular signal-regulated kinase, c-jun N-terminal kinases, and p38). ${ }^{36}$ These MAPK subfamilies play an important role in collagen production. ${ }^{20,21,37,38}$ p38 MAPK and extracellular signal-regulated kinase are known to regulate ECM deposition via interaction with the TGF- $\beta$ pathway. ${ }^{38}$ However, among the three major MAPK families, only p38 MAPK plays a positive role in the production of collagen in human dermal fibroblasts. Extracellular signal-regulated kinase activation has been shown to inhibit collagen gene expression. $^{20,39}$ In addition, negative regulation of the $\mathrm{c}$-jun $\mathrm{N}$-terminal kinase signaling pathway has been demonstrated in the production of collagen from dermal fibroblasts. ${ }^{40,41}$ Thus, among the MAPK families, p38 MAPK is the most promising candidate for the treatment of SSc. SSc fibroblasts have been reported to show constitutive phosphorylation and activation of p38 MAPK..$^{20,22}$ Furthermore, activated p38 MAPK in SSc fibroblasts was correlated with increased expression of type I collagen and fibronectin $1 .^{21}$ Taken together, these previous studies suggested the possibility of p38 MAPK inhibitor therapy for SSc. VX-702 selectively inhibits the $\mathrm{p} 38 \alpha$ isoform. The current study showed that VX-702-mediated p38 MAPK inhibition dramatically prevented the development of skin fibrosis in murine SclcGVHD mice. In addition, p38 MAPK inhibition directly suppressed collagen synthesis from fibroblasts. In contrast, it was reported that a p38 MAPK inhibitor ameliorated bleomycin-induced pulmonary fibrosis ${ }^{42,43}$ and renal fibrosis $^{44,45}$ in mouse and rat models. A p38 MAPK inhibitor has also been reported to reduce fibrosis after rotator cuff injury in rats. ${ }^{46}$ Thus, p38 MAPK inhibitors might be effective for not only SSc but also for other fibrotic diseases. Indeed, pirfenidone, a small-molecule p38 kinase inhibitor, has already been approved in Europe, United States, and Japan for treatment of idiopathic pulmonary fibrosis. ${ }^{47}$ Alternatively, a p38 MAPK inhibitor attenuated the allergic inflammatory response in a mouse model of asthma. ${ }^{48}$ The current study showed that p38 MAPK inhibition suppressed the contact hypersensitivity response (Supplemental Figure S2). Therefore, administration of a p38 MAPK inhibitor might be useful for not only fibrotic diseases but also allergic diseases. Nonetheless, VX-702 is a potent candidate for the treatment of SSc.

Although p38 MAPK inhibitors have a beneficial effect in fibrotic diseases and inflammatory diseases via regulation of 

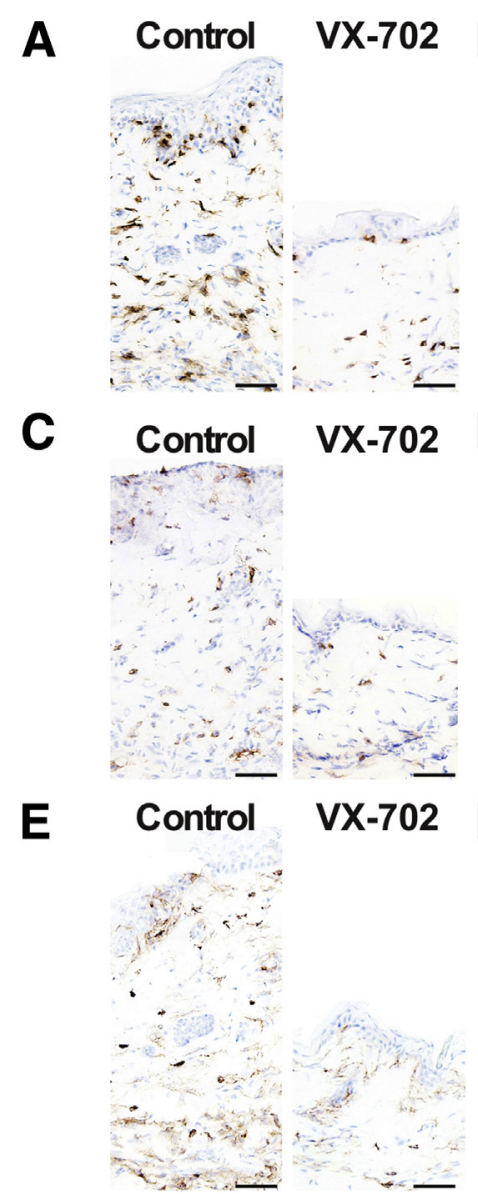

G
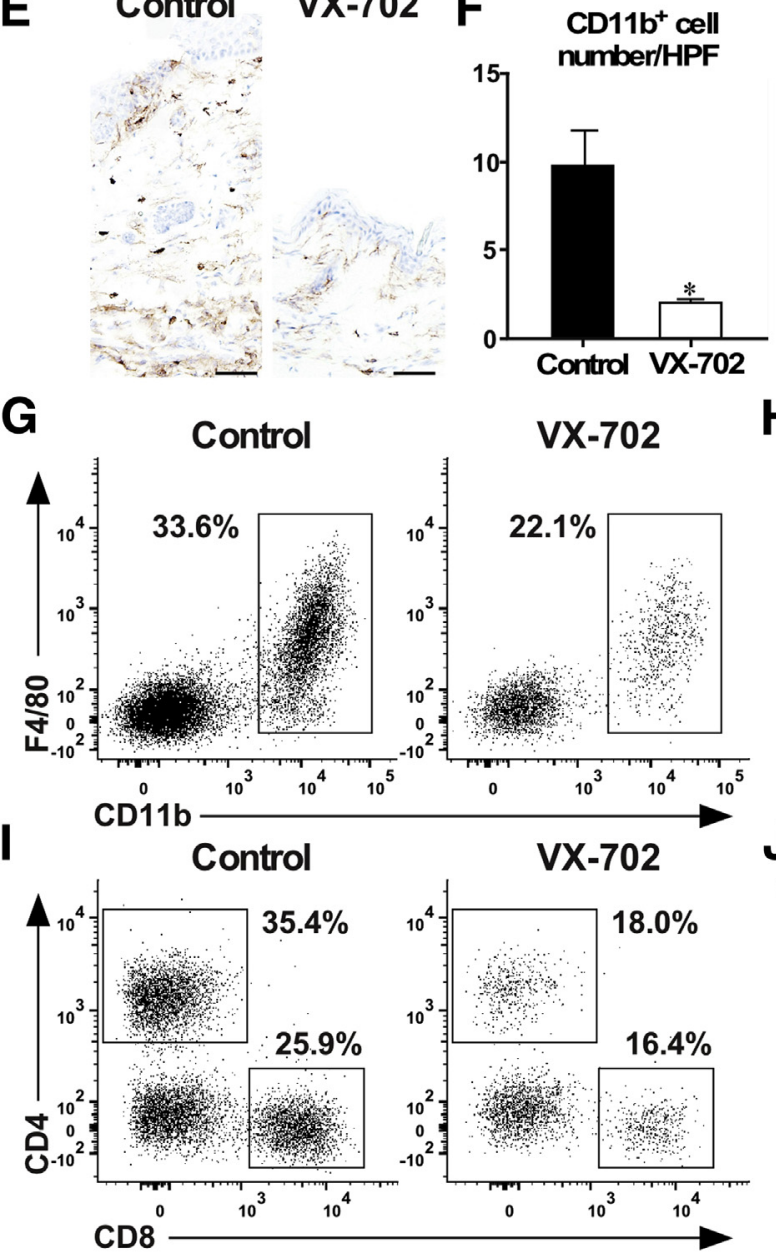

Figure 4 The p38 MAPK inhibitor suppresses the infiltration of immune cells into the skin on Scl-cGVHD mice. A-F: Representative immunohistochemical staining of the skin. Skin tissues were harvested 36 days after bone marrow transplantation (BMT). The number of $\mathrm{CD}^{+}$cells (A and $\mathbf{B}), \mathrm{CD}^{+} \mathrm{T}$ cells ( $\mathbf{C}$ and $\left.\mathbf{D}\right)$, and $\mathrm{CD} 11 \mathrm{~b}^{+}$cells (E and $\mathbf{F}$ ) per high-power field (HPF) in immunohistochemical-stained slides from groups of water-treated or VX-702-treated mice. G-K: Results for fluorescence-activated cell sorting analysis of skin-infiltrating cells are shown. Representative results demonstrate the frequency of skin-infiltrating $\mathrm{CD}_{11} \mathrm{~b}^{+}$cells $(\mathbf{G}), \mathrm{CD}^{+}$cells $(\mathrm{I})$, and $\mathrm{CDB}^{+} \mathrm{T}$ cells $(\mathbf{I})$. Numbers of skin $\mathrm{CD}_{11 b^{+}}$cells (H), $\mathrm{CD}^{+}$cells $(\mathbf{J})$, and $\mathrm{CD}^{+} \mathrm{T}$ cells $(\mathbf{K}) 36$ days after BMT are also shown. All data are representative of two independent experiments. Data are expressed as means \pm SEM (B, D, F, H, J, and $\mathbf{K})$. $n=4$ to 6 mice per group $(\mathbf{H}, \mathbf{J}$, and $\mathbf{K})$. ${ }^{*} P<0.05,{ }^{* *} P<0.01$. Scale bar $=50 \mu \mathrm{m}(\mathbf{A}, \mathbf{C}$, and $\mathbf{E})$.

\section{H}
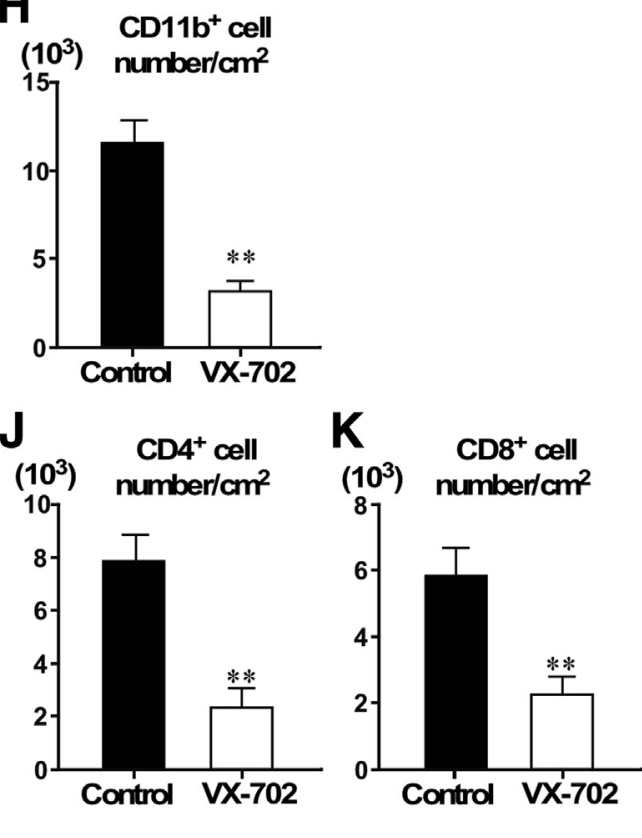

cytokine production and fibroblast activity, there is a possibility that p38 MAPK inhibitors may have harmful effects in the gut. It has been reported that a p38 MAPK inhibitor worsened weight loss in trinitrobenzene sulfonic acid-induced colitis ${ }^{49}$ and dextran sulfate sodium-induced colitis $^{50}$ by affecting intestinal intraepithelial lymphocytes, resulting in increased gut cytotoxicity. In contrast, a p38 MAPK inhibitor was shown to improve dextran sulfate 

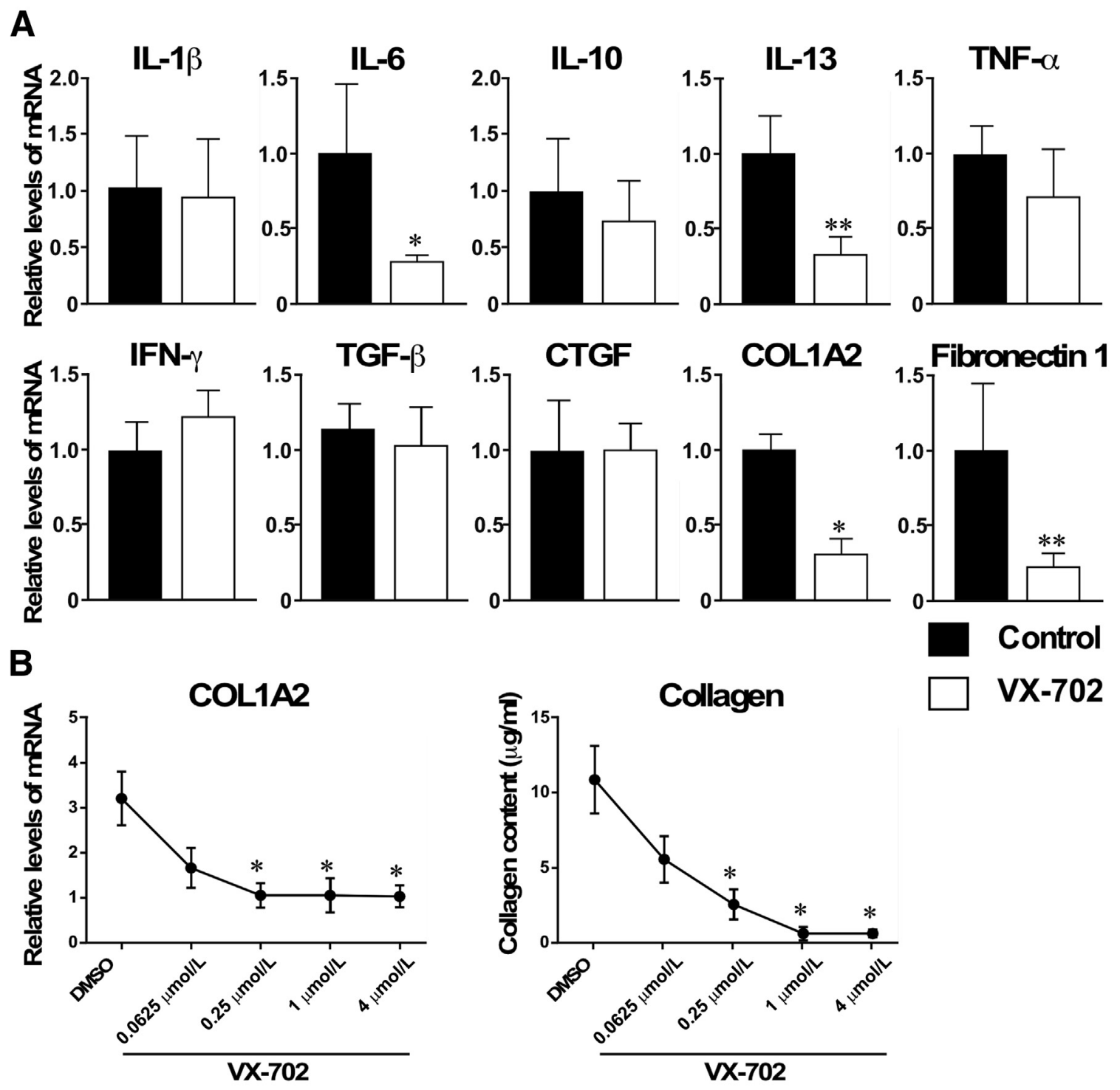

Figure 5 The p38 MAPK directly inhibits the collagen synthesis from fibroblast. A: Expression of mRNA for IL-1 $\beta$, IL-6, IL-10, IL-13, tumor necrosis factor (TNF)- $\alpha$, interferon (IFN) $-\gamma$, transforming growth factor (TGF)- $\beta$, connective tissue growth factor (CTGF), pro 22 (I) collagen (COL1A2), and fibronectin 1 in the skin 36 days after bone marrow transplantation. B: Cultured dermal fibroblasts were pretreated with dimethyl sulfoxide (DMSO) or various concentration of VX702. One hour later, cells were stimulated with $10 \mathrm{ng} / \mathrm{mL}$ TGF- $\beta 2$ and incubated for another 24 hours. Total RNA was extracted and expression of mRNA for COL1A2 was quantitatively analyzed by real-time RT-PCR. Collagen content of fibroblast culture supernatant was determined by hydroxyproline assay. Each sample was analyzed in triplicate. Significance is shown versus fibroblasts with DMSO only. All data are representative of two independent experiments. Data are expressed as means \pm SEM. $n=4$ to 6 mice per group $(\mathbf{A}) .{ }^{*} P<0.05,{ }^{*} P<0.01$.

sodium-induced colitis associated with down-regulation of cytokine production. ${ }^{51}$ The current study showed that a $\mathrm{p} 38$ MAPK inhibitor significantly improved body weight loss and gut fibrosis (Figure 2B and Figure 3). Therefore, p38 MAPK inhibition has a beneficial effect in a Scl-cGVHD model.

The phosphorylation of p38 MAPK results in the transcriptional activation of cytokines, ${ }^{11,52}$ such as tumor necrosis factor- $\alpha$, IL-1, and IL- 6 , which play an important role in rheumatoid arthritis pathogenesis. Several studies have shown that the p38 MAPK inhibition suppresses cytokine production. ${ }^{53}$ The current study also showed that the p38 MAPK inhibitor attenuated mRNA expression of fibrogenic cytokines, such as IL-6 and IL-13, in the skin of Scl-cGVHD mice. In patients with rheumatoid arthritis, p38 MAPK phosphorylation and activation have been demonstrated in synovial tissues. ${ }^{54}$ Furthermore, blockade of p38 MAPK has been shown to suppress both paw swelling and joint damage in rat models of rheumatoid arthritis. ${ }^{11,55}$ These results indicated that p38 MAPK inhibitors might have therapeutic benefits for patients with rheumatoid arthritis. In a human clinical study, VX-702 was found to be clinically safe and to induce a rapid reduction in the levels of inflammation biomarkers, such as C-reactive protein, the soluble $55-\mathrm{kDa}$ isoform of tumor necrosis factor receptor, and serum amyloid A as early as week 2 of administration, 
although these effects were not sustained over the longterm. ${ }^{16}$ This result indicates that the inhibition of $\mathrm{p} 38$ MAPK in rheumatoid arthritis patients might have an acute transient effect. The most plausible explanation for the limited effect is the redundancy of signaling networks, such that p38 MAPK blockade might redirect the alternative signaling flow. This aspect needs to be studied and manipulated in future clinical studies.

To conclude, we demonstrated that treatment with VX-702 effectively reduced Scl-cGVHD severity and fibrosis. Blockade of p38 $\alpha$ MAPK suppressed the infiltration of immune cells into the skin in Scl-cGVHD mice. In addition, we showed that collagen synthesis from fibroblasts was reduced by the blockade of p38 $\alpha$ MAPK signaling. Thus, the p38 MAPK inhibitor VX-702 might be a promising candidate for use in treating patients with Scl-cGVHD and SSc.

\section{Acknowledgments}

We thank Masako Matsubara and Yuko Yamada for technical assistance.

\section{Supplemental Data}

Supplemental material for this article can be found at http://dx.doi.org/10.1016/j.ajpath.2016.12.016.

\section{References}

1. LeRoy EC, Black C, Fleischmajer R, Jablonska S, Krieg T, Medsger TA Jr, Rowell N, Wollheim F: Scleroderma (systemic sclerosis): classification, subsets, and pathogenesis. J Rheumatol 1988, 15:202-205

2. Ihn H: The role of TGF-beta signaling in the pathogenesis of fibrosis in scleroderma. Arch Immunol Ther Exp (Warsz) 2002, 50:325-331

3. Furst DE, Clements PJ: Hypothesis for the pathogenesis of systemic sclerosis. J Rheumatol 1997, 24(Suppl 48):53-57

4. Yamamoto T: Characteristics of animal models for scleroderma. Curr Rheumatol Rev 2005, 1:101-109

5. Claman HN, Jaffee BD, Huff JC, Clark RA: Chronic graft-versushost disease as a model for scleroderma, II: mast cell depletion with deposition of immunoglobulins in the skin and fibrosis. Cell Immunol 1985, 94:73-84

6. Anderson BE, McNiff J, Yan J, Doyle H, Mamula M, Shlomchik MJ, Shlomchik WD: Memory CD4+ T cells do not induce graft-versushost disease. J Clin Invest 2003, 112:101-108

7. Le Huu D, Matsushita T, Jin G, Hamaguchi Y, Hasegawa M, Takehara K, Tedder TF, Fujimoto M: Donor-derived regulatory B cells are important for suppression of murine sclerodermatous chronic graft-versus-host disease. Blood 2013, 121:3274-3283

8. Rouse J, Cohen P, Trigon S, Morange M, Alonso-Llamazares A, Zamanillo D, Hunt T, Nebreda AR: A novel kinase cascade triggered by stress and heat shock that stimulates MAPKAP kinase-2 and phosphorylation of the small heat shock proteins. Cell 1994, 78: $1027-1037$

9. Freshney NW, Rawlinson L, Guesdon F, Jones E, Cowley S, Hsuan J, Saklatvala J: Interleukin-1 activates a novel protein kinase cascade that results in the phosphorylation of Hsp27. Cell 1994, 78: 1039-1049
10. Han J, Lee JD, Bibbs L, Ulevitch RJ: A MAP kinase targeted by endotoxin and hyperosmolarity in mammalian cells. Science 1994, 265:808-811

11. Lee JC, Laydon JT, McDonnell PC, Gallagher TF, Kumar S, Green D, McNulty D, Blumenthal MJ, Keys JR, Landvatter SW, Strickler JE, McLaughlin MM, Siemens IR, Fisher SM, Livi GP, White JR, Adams JL, Young PR: A protein kinase involved in the regulation of inflammatory cytokine biosynthesis. Nature 1994, 372: 739-746

12. Li M, Liu J, Zhang C: Evolutionary history of the vertebrate mitogen activated protein kinases family. PLoS One 2011, 6:e26999

13. Ono K, Han J: The p38 signal transduction pathway: activation and function. Cell Signal 2000, 12:1-13

14. Raingeaud J, Gupta S, Rogers JS, Dickens M, Han J, Ulevitch RJ, Davis RJ: Pro-inflammatory cytokines and environmental stress cause p38 mitogen-activated protein kinase activation by dual phosphorylation on tyrosine and threonine. J Biol Chem 1995, 270:7420-7426

15. Zervos AS, Faccio L, Gatto JP, Kyriakis JM, Brent R: Mxi2, a mitogen-activated protein kinase that recognizes and phosphorylates Max protein. Proc Natl Acad Sci U S A 1995, 92:10531-10534

16. Damjanov N, Kauffman RS, Spencer-Green GT: Efficacy, pharmacodynamics, and safety of VX-702, a novel p38 MAPK inhibitor, in rheumatoid arthritis: results of two randomized, double-blind, placebo-controlled clinical studies. Arthritis Rheum 2009, 60: $1232-1241$

17. Ding C: Drug evaluation: VX-702, a MAP kinase inhibitor for rheumatoid arthritis and acute coronary syndrome. Curr Opin Investig Drugs 2006, 7:1020-1025

18. Genovese MC, Cohen SB, Wofsy D, Weinblatt ME, Firestein GS, Brahn E, Strand V, Baker DG, Tong SE: A 24-week, randomized, double-blind, placebo-controlled, parallel group study of the efficacy of oral SCIO-469, a p38 mitogen-activated protein kinase inhibitor, in patients with active rheumatoid arthritis. J Rheumatol 2011, 38: 846-854

19. Cohen SB, Cheng TT, Chindalore V, Damjanov N, Burgos-Vargas R, Delora P, Zimany K, Travers H, Caulfield JP: Evaluation of the efficacy and safety of pamapimod, a p38 MAP kinase inhibitor, in a double-blind, methotrexate-controlled study of patients with active rheumatoid arthritis. Arthritis Rheum 2009, 60:335-344

20. Sato M, Shegogue D, Gore EA, Smith EA, McDermott PJ, Trojanowska M: Role of p38 MAPK in transforming growth factor beta stimulation of collagen production by scleroderma and healthy dermal fibroblasts. J Invest Dermatol 2002, 118:704-711

21. Ihn H, Yamane K, Tamaki K: Increased phosphorylation and activation of mitogen-activated protein kinase p38 in scleroderma fibroblasts. J Invest Dermatol 2005, 125:247-255

22. Le Huu D, Matsushita T, Jin G, Hamaguchi Y, Hasegawa M, Takehara K, Fujimoto M: IL-6 blockade attenuates the development of murine sclerodermatous chronic graft-versus-host disease. J Invest Dermatol 2012, 132:2752-2761

23. Matsushita Y, Hasegawa M, Matsushita T, Fujimoto M, Horikawa M, Fujita T, Kawasuji A, Ogawa F, Steeber DA, Tedder TF, Takehara K, Sato S: Intercellular adhesion molecule-1 deficiency attenuates the development of skin fibrosis in tight-skin mice. J Immunol 2007, 179: 698-707

24. Zhang Y, McCormick LL, Desai SR, Wu C, Gilliam AC: Murine sclerodermatous graft-versus-host disease, a model for human scleroderma: cutaneous cytokines, chemokines, and immune cell activation. J Immunol 2002, 168:3088-3098

25. Hasegawa M, Fujimoto M, Matsushita T, Hamaguchi Y, Takehara K, Sato S: Serum chemokine and cytokine levels as indicators of disease activity in patients with systemic sclerosis. Clin Rheumatol 2011, 30: 231-237

26. Matsushita T, Hasegawa M, Hamaguchi Y, Takehara K, Sato S: Longitudinal analysis of serum cytokine concentrations in systemic sclerosis: association of interleukin 12 elevation with spontaneous regression of skin sclerosis. J Rheumatol 2006, 33:275-284 
27. Horikawa M, Hasegawa M, Komura K, Hayakawa I, Yanaba K Matsushita T, Takehara K, Sato S: Abnormal natural killer cell function in systemic sclerosis: altered cytokine production and defective killing activity. J Invest Dermatol 2005, 125:731-737

28. Beutler B, Cerami A: Cachectin and tumour necrosis factor as two sides of the same biological coin. Nature 1986, 320:584-588

29. Duncan MR, Berman B: Differential regulation of collagen, glycosaminoglycan, fibronectin, and collagenase activity production in cultured human adult dermal fibroblasts by interleukin 1-alpha and beta and tumor necrosis factor-alpha and beta. J Invest Dermatol 1989, 92:699-706

30. Ong CJ, Ip S, Teh SJ, Wong C, Jirik FR, Grusby MJ, Teh HS: A role for T helper 2 cells in mediating skin fibrosis in tight-skin mice. Cell Immunol 1999, 196:60-68

31. Matsushita T, Fujimoto M, Hasegawa M, Matsushita Y, Komura K, Ogawa F, Watanabe R, Takehara K, Sato S: BAFF antagonist attenuates the development of skin fibrosis in tight-skin mice. J Invest Dermatol 2007, 127:2772-2780

32. Takehara K: Hypothesis: pathogenesis of systemic sclerosis. J Rheumatol 2003, 30:755-759

33. Wynn TA: Fibrotic disease and the $\mathrm{T}(\mathrm{H}) 1 / \mathrm{T}(\mathrm{H}) 2$ paradigm. Nat Rev Immunol 2004, 4:583-594

34. Badea I, Virtanen C, Verrall RE, Rosenberg A, Foldvari M: Effect of topical interferon-gamma gene therapy using gemini nanoparticles on pathophysiological markers of cutaneous scleroderma in Tsk/+ mice. Gene Ther 2012, 19:978-987

35. Yamamoto T, Takagawa S, Kuroda M, Nishioka K: Effect of interferon-gamma on experimental scleroderma induced by bleomycin. Arch Dermatol Res 2000, 292:362-365

36. Firestein GS, Manning AM: Signal transduction and transcription factors in rheumatic disease. Arthritis Rheum 1999, 42:609-621

37. Chen A, Davis BH: UV irradiation activates JNK and increases alphaI(I) collagen gene expression in rat hepatic stellate cells. J Biol Chem 1999, 274:158-164

38. Hayashida T, Poncelet AC, Hubchak SC, Schnaper HW: TGF-beta1 activates MAP kinase in human mesangial cells: a possible role in collagen expression. Kidney Int 1999, 56:1710-1720

39. Reunanen N, Foschi M, Han J, Kahari VM: Activation of extracellular signal-regulated kinase 1/2 inhibits type I collagen expression by human skin fibroblasts. J Biol Chem 2000, 275:34634-34639

40. Davis RJ: Signal transduction by the JNK group of MAP kinases. Cell 2000, 103:239-252

41. Fisher GJ, Datta S, Wang Z, Li XY, Quan T, Chung JH, Kang S, Voorhees JJ: c-Jun-dependent inhibition of cutaneous procollagen transcription following ultraviolet irradiation is reversed by all-trans retinoic acid. J Clin Invest 2000, 106:663-670

42. Matsuoka H, Arai T, Mori M, Goya S, Kida H, Morishita H, Fujiwara H, Tachibana I, Osaki T, Hayashi S: A p38 MAPK inhibitor, FR-167653, ameliorates murine bleomycin-induced pulmonary fibrosis. Am J Physiol Lung Cell Mol Physiol 2002, 283: L103-L112
43. Underwood DC, Osborn RR, Bochnowicz S, Webb EF, Rieman DJ, Lee JC, Romanic AM, Adams JL, Hay DWP, Griswold DE: SB 239063, a p38 MAPK inhibitor, reduces neutrophilia, inflammatory cytokines, MMP-9, and fibrosis in lung. Am J Physiol Lung Cell Mol Physiol 2000, 279:L895-L902

44. Nishida M, Okumura Y, Sato H, Hamaoka K: Delayed inhibition of p38 mitogen-activated protein kinase ameliorates renal fibrosis in obstructive nephropathy. Nephrol Dial Transplant 2008, 23: $2520-2524$

45. Stambe C, Atkins RC, Tesch GH, Masaki T, Schreiner GF, NikolicPaterson DJ: The role of p38 alpha mitogen-activated protein kinase activation in renal fibrosis. J Am Soc Nephrol 2004, 15:370-379

46. Wilde JM, Gumucio JP, Grekin JA, Sarver DC, Noah AC, Ruehlmann DG, Davis ME, Bedi A, Mendias CL: Inhibition of p38 mitogen-activated protein kinase signaling reduces fibrosis and lipid accumulation after rotator cuff repair. J Shoulder Elbow Surg 2016, 25:1501-1508

47. Moran N: p38 Kinase inhibitor approved for idiopathic pulmonary fibrosis. Nat Biotechnol 2011, 29:301

48. Ma JY, Medicherla S, Kerr I, Mangadu R, Protter AA, Higgins LS: Selective p38alpha mitogen-activated protein kinase inhibitor attenuates lung inflammation and fibrosis in IL-13 transgenic mouse model of asthma. J Asthma Allergy 2008, 1:31-44

49. ten Hove T, van den Blink B, Pronk I, Drillenburg P, Peppelenbosch MP, van Deventer SJH: Dichotomal role of inhibition of p38 MAPK with SB 203580 in experimental colitis. Gut 2002, 50:507-512

50. Nishimura $T$, Andoh A, Nishida A, Shioya M, Koizumi Y, Tsujikawa T, Fujiyama Y: FR167653, a p38 mitogen-activated protein kinase inhibitor, aggravates experimental colitis in mice. World $\mathrm{J}$ Gastroenterol 2008, 14:5851-5856

51. Hollenbach E, Neumann M, Vieth M, Roessner A, Malfertheiner P, Naumann M: Inhibition of p38 MAP kinase- and RICK/NF-kappa Bsignaling suppresses inflammatory bowel disease. FASEB J 2004, 18: $1550-1552$

52. Beyaert R, Cuenda A, Vanden Berghe W, Plaisance S, Lee JC, Haegeman G, Cohen P, Fiers W: The p38/RK mitogen-activated protein kinase pathway regulates interleukin-6 synthesis response to tumor necrosis factor. EMBO J 1996, 15:1914-1923

53. Thalhamer T, McGrath MA, Harnett MM: MAPKs and their relevance to arthritis and inflammation. Rheumatology 2008, 47: 409-414

54. Schett G, Tohidast-Akrad M, Smolen JS, Schmid BJ, Steiner CW, Bitzan P, Zenz P, Redlich K, Xu Q, Steiner G: Activation, differential localization, and regulation of the stress-activated protein kinases, extracellular signal-regulated kinase, c-JUN N-terminal kinase, and p38 mitogen-activated protein kinase, in synovial tissue and cells in rheumatoid arthritis. Arthritis Rheum 2000, 43:2501-2512

55. Nishikawa $M$, Myoui A, Tomita $T$, Takahi $K$, Nampei $A$, Yoshikawa H: Prevention of the onset and progression of collageninduced arthritis in rats by the potent $\mathrm{p} 38$ mitogen-activated protein kinase inhibitor FR167653. Arthritis Rheum 2003, 48:2670-2681 